\title{
Alcance del Sistema Nacional Anticorrupción SNA en la Soberanía de los Estados y la Autonomía Hacendaria Municipal ${ }^{1}$
}

\author{
Adria Velia González Beltrones Guadalupe Aleida Valenzuela Miranda, \\ María Dolores Rocha Ontiveros ${ }^{2}$, Jesús Miguel Maya Rodríguez ${ }^{3}$ \\ Frecuentemente se piensa que se está a merced de la corrupción y de \\ que esta no es más que un "modo de vida". Sin embargo, toda \\ sociedad, todo sector y todo ciudadano se beneficiarían si rompieran \\ la cadena de la corrupción en su vida diaria. UNODC Oficina de las \\ Naciones Unidas Contra la Droga y el Delito Anexo 1
}

\section{Resumen}

En el documento se reflexiona brevemente sobre la reforma constitucional que da nacimiento al Sistema Nacional Anticorrupción SNA y su impacto en la soberanía de los Estados y la autonomía hacendaria de los Municipios, espacios en los que si bien también se presenta el grave problema de la corrupción, ello no obsta para que en algunos aspectos muy específicos, se invada la esfera de competencias de los estados y municipios, como es el caso de la fiscalización de las participaciones, facultad atribuida a la Auditoria Superior de la Federación ASF, socavando con ello el pacto federal y por ende el estado de derecho.

Palabras clave: Sistema Nacional Anticorrupción SNA, invasión de competencias, estado de derecho

${ }^{1}$ Ponencia Presentada en el Primer Congreso Mundial Derecho Administrativo. Universidad de Guanajuato, Instituto de Investigaciones Jurídicas de la Universidad Nacional Autónoma de México, Foro Iberoamericano de Derecho Administrativo, Asociación Internacional de Derecho Administrativo, Asociación Interamericana de Derecho Administrativo, Asociación Iberoamericana de Derecho Administrativo, Asociación Mexicana de Derecho Administrativo y Tribunal de lo Contencioso Administrativo del Estado de Guanajuato. Días 10, 11 y 12 de agosto de 2016 en la sede de la División de Derecho, Política y Gobierno de la Universidad de Guanajuato.

${ }^{2}$ Docentes - Investigadoras del Departamento de Derecho y del Departamento de Sociología y Administración Pública de la DCS de la URC de la Universidad de Sonora.

${ }^{3}$ Estudiante de Doctorado en desarrollo Regional y Ciencias Sociales del COLSON 


\section{Introducción}

¿Cómo romper la cadena de la corrupción? Consideramos que este cuestionamiento habrá de ser respondido desde diferentes perspectivas de los participantes reunidos -- en este Primer Congreso Mundial de Derecho Administrativo--, en este sobrio recinto del edificio de la Universidad de Guanajuato, según el orden del Programa cuya temática es el Combate a la Corrupción.

Estamos a escasos días de que se cumpla un mes de la afirmación ---en Palacio Nacional --del Presidente de México Enrique Peña nieto, "si queremos recuperar la confianza ciudadana, todos tenemos que ser autocríticos, tenemos que mirarnos en el espejo, empezando por el propio Presidente de la República. ${ }^{4}$

El propósito intrínseco de la gran cantidad de modificaciones a nuestro sistema normativo en el mas alto nivel, lo es, seguramente el instaurar un nuevo paradigma normativo y axiológico de control del Estado -- con miras a recuperar la confianza institucional -- ante la innumerable cantidad de los actos de corrupción e impunidad en la función pública ${ }^{5}$,que poco a poco han minado la confianza de los ciudadanos en los servidores públicos.

En palabras del Doctor Fernández Ruiz "no es suficiente la existencia de una Constitución, entendida como ley suprema, para asegurar que los depositarios de las funciones del poder público se abstengan de abusar de su ejercicio en perjuicio de las libertades y derechos de los seres humanos, porque para ello se requiere la existencia de mecanismos jurídicos de defensa constitucional que aseguren la

${ }^{4}$ al promulgar en Palacio Nacional el 18 de julio de 2016,las siete leyes que conforman el Sistema Nacional Anticorrupción SNA. Consultado en el portal de RRC -CIDE [on line] Disponible en: http://rendiciondecuentas.org.mx/sistemanacional-anticorrupcion/

${ }^{5}$ con la participación indubitable de algunos integrantes de los otros sectores de nuestra sociedad, según lo han señalado organismos nacionales e internacionales como la ONU.OCDE, TI;IMCO etc., y asimismo dan testimonio de ello la gran cantidad de notas periodísticas o editoriales de los principales medios locales y nacionales alusivos a actos de corrupción en nuestro país 
efectiva vigencia de esa ley suprema en aras de una convivencia social humana, justa y ordenada. ${ }^{6}$

Sin embargo , ...como afirma RODRIGUEZ -ARANA, la Administración Pública no es mas que un reflejo de la sociedad. El propio ambiente social [fomento del consumismo, valoración de las personas en razón de su éxito económico...] hace indispensable una reflexión sobre los valores y sobre la forma en que han calado en los grupos sociales, e influyen en la actuación pública a través de sus servidores que, como es lógico también son ciudadanos"7.

Al decir de Transparencia Internacional TI, México se encuentra en la posición 95 de 168 países en el Índice de Percepción de la Corrupción 2015.La calificación que obtuvo fue de 35 sobre 100 puntos en una escala donde 0 es una percepción de altos niveles de corrupción y 100 percepción de bajos niveles de corrupción. ${ }^{8}$

Si bien es cierto que “... la pérdida de valores en el ejercicio de la función pública es especialmente grave y negativa para la sociedad por lo que supone de perversión de la actividad de los servidores públicos y el ejemplo negativo que supone para todos los ciudadanos, también es cierto que ....la ciudadanía hoy es consciente y clama por la regeneración de la vida pública y las bases éticas de

${ }^{6}$ Entre los referidos mecanismos destacan, en el orden jurídico mexicano, el amparo, la controversia constitucional, la acción de inconstitucionalidad y el juicio para la protección de los derechos político-electorales de los ciudadanos, FERNANDEZ RUIZ J., Prólogo en Justicia Constitucional Local, Corona Nakamira L.A. et al. Coed Instituto Prisciliano Sánchez ,UNAM México 2013,pp. 6

${ }^{7}$ RODRIGUEZ -ARANA,J., Cuestiones deontológicas en torno al trabajo en la Administración Pública" en Etica de las profesiones jurídicas (dos Vol.) Universidad católica de Murcia 2003, citado por Junquera de Estéfani R., et al, en Ética y Deontología Públicas, pp 220, Ed.Universitas,S.A., Madrid, 2011

${ }^{8}$ Este índice se elabora a partir de las opiniones de expertos sobre la corrupción en el sector público y examina aspectos como el gobierno abierto, rendición de cuentas, libertad de expresión, transparencia, niveles de integridad en el servicio público y acceso igualitario a la justicia. 
nuestra democracia", prueba de ello lo es la eficacia en su participación en nuestro país ${ }^{9}$

\section{Objetivo}

En este contexto, se enmarca nuestra participación, en el sentido de reflexionar brevemente sobre la reforma constitucional que da nacimiento al SNA y su impacto en la soberanía de los Estados y la autonomía hacendaria de los Municipios, espacios en donde si bien también se presenta el grave problema de la corrupción, ello no obsta para que en algunos aspectos muy específicos, se invada la esfera de competencias de los estados y municipios, como lo es entre otros, el caso de la fiscalización de las participaciones, socavando con ello el pacto federal y por ende el estado de derecho.

De todos es sabido que el 27 de mayo del 2015 y después de un proceso legislativo extenso --en número de iniciativas y de tiempo--, se publicó finalmente en el Diario Oficial de la Federación DOF el Sistema Nacional Anticorrupción SNA, que busca, en principio, coordinar los esfuerzos de los tres órdenes de gobierno para el combate a la corrupción. Con ello se pretende dar respuesta a una de las demandas más sentidas de la sociedad de la ingente necesidad de acabar con la lamentable corrupción campeante ya en todos sus ámbitos .

Indudablemente de la reforma surgen más dudas que certidumbre sobre las estrategias a seguir para combatir la corrupción, no sólo por lo que respecta a las dependencias del Ejecutivo sino también por lo que corresponde realizar al órgano de control del poder Legislativo, a las nuevas instituciones encargadas de

\footnotetext{
${ }^{9}$ Más de 634 mil personas que confiaron en la vía institucional para promover la primera iniciativa ciudadana que es dictaminada y votada en el Congreso, y a partir de hoy, la primera en la historia del país que es promulgada. Mensaje de las organizaciones académicas y civiles con motivo de la promulgación del primer paquete de reformas anticorrupción en voz de Eduardo Bohórquez Transparencia Mexicana TM , en su intervención en palacio nacional el 18 de julio de 2016.
} 
las fiscalizaciones o sanciones, al Consejo de la Judicatura del Poder Judicial, a sus homólogos en las entidades federativas y demás órganos autónomos y sectores de la sociedad civil involucrados en el SNA ${ }^{10}$.

\section{Planteamiento del Problema}

El Sistema Nacional Anticorrupción en teoría deberá contribuir a que el uso de recursos públicos atienda efectivamente los propósitos para los cuales están destinados. En esta perspectiva, el SNA llama a recuperar la confianza institucional con espíritu de apertura, transparencia y ciudadanización del ejercicio del quehacer público, sin embargo no debemos soslayar que ello es un golpe mas al Federalismo.

\section{A manera de Hipótesis}

${ }^{10}$ En la creación del SNA se observa la ambivalencia de opiniones en cuanto al reparto de competencias de nuestro sistema federal. Si bien se concibe como una instancia nacional de coordinación entre las autoridades de todos los órdenes de gobierno (federal, estatal y municipal), respetando en principio el federalismo dual, al considerar que las 32 entidades federativas establezcan sistemas locales anticorrupción. Es decir, se prevé la existencia de dos sistemas anticorrupción, uno nacional y otro local. No obstante, que se dispone en el Artículo 113 de la CPEUM que el SNA cuente con un Comité Coordinador, (integrado por los titulares de la Auditoría Superior de la Federación; de la Fiscalía Especializada en Combate a la Corrupción; de la secretaría del Ejecutivo Federal responsable del control interno; por el presidente del Tribunal Federal de Justicia Administrativa; el presidente del organismo garante que establece el artículo 6o. de esta Constitución; así como por un representante del Consejo de la Judicatura Federal y otro del Comité de Participación Ciudadana), con atribuciones, entre otras, para diseño y promoción de políticas integrales en materia de fiscalización y control de recursos públicos; para determinar los mecanismos de intercambio de información y el establecimiento de bases y principios para la efectiva coordinación de las autoridades de los órdenes de gobierno entre otras, pero sin la representatividad de los gobiernos estatales ni municipales en ese nivel de toma de decisiones tan importantes, esquema que a su vez repicaran las Entidades Federativas, dejando fuera también en ese nivel de toma de decisiones a los municipios. Decreto por el que se reforman, adicionan y derogan diversas disposiciones de la Constitución Política de los Estados Unidos Mexicanos, en materia de combate a la corrupción”, publicado en el Diario Oficial de la Federación de 27 de julio de 2015, 
Esto es así puesto que una vez mas ${ }^{11}$ con el consentimiento de los representantes del pueblo y con el consentimiento de los representantes de los intereses de las entidades federativas ante el Congreso de la Unión se distorsiona nuestro federalismo suigéneris ${ }^{12}$ al dar mayor intervención a las autoridades centrales o nacionales en su ámbito jurídico político, so pretexto de combatir la corrupción y sin atajar en específico, la falta de transparencia en la asignación y distribución de los recursos de la Federación a las entidades federativas, y de éstas a los municipios y demarcaciones territoriales, así como en las tareas de

${ }^{11}$ Recordemos las recientes reformas al Instituto Nacional Electoral INE y al Instituto Nacional de Transparencia, Acceso a la Información y Protección de Datos Personales INAI, lo que hace visible la tendencia asumida por el Poder Legislativo hacia una mayor concentración de atribuciones en favor de las autoridades federales. Sin descartar -- que de igual forma -- en que los órganos locales electorales, fueron desaparecidos, so pretexto de señalamientos sobre la injerencia de los gobernadores o partidos políticos locales en su organización y atribuciones, en un futuro, la actual Auditoría Superior de la Federación ASF, se convierta en una auditoría superior nacional y que los titulares de órganos fiscalizadores locales sean nombrados por aquella. De igual manera criticable, la desafortunada decisión tomada a favor de que, el nuevo Instituto Nacional de Transparencia sea el facultado para revisar las resoluciones de los Órganos Garantes de Transparencia Locales, sin descartar que en un futuro, en un descuido político de las Entidades Federativas al nuevo Tribunal Federal de Justicia Administrativa, se le convierta en un tribunal nacional y también se le faculte para revisar las resoluciones de los tribunales locales de justicia administrativa.

12 Acorde con lo citado por el distinguido jurisconsulto Margain Manautou E., en su obra Introducción al Estudio del Derecho Tributario: "Al sistema federal mexicano se le han pretendido encontrar puntos de semejanza con el norteamericano o el canadiense. En efecto al consumarse la Independencia el 27 de septiembre de 1821 , no surgieron varios estados independientes entre sí, sino uno solo; los diputados constituyentes de 1822 no representaban entidad alguna. Con el Con el derrumbe del Imperio y reunido nuevamente el Constituyente, éste se decidió a implantar el sistema federal, el cual surgió, no como que el Estado Unitario daba vida a los Estados Federales, sino como que éstos daban vida al órgano federal. De ahí que Tena Ramírez en su obra denominada Derecho Constitucional Mexicano, exprese que "al promulgarse el Acta nacieron los Estados y simultáneamente la Federación". Por lo tanto se adoptó el principio de que las facultades no delegadas a la federación, se entienden reservadas a los Estados; principio que se encuentra incorporado en el Artículo 124 de la Constitución Mexicana de 1917. 
planeación e implementación estratégica de los programas relativos.

\section{Elaboración / constatación de las hipótesis:}

1) En materia de fiscalización de los recursos públicos, conforme a lo estipulado en la reciente reforma del artículo 79 Fracción I de nuestra Carta Magna ${ }^{13}$, se contraviene el pacto federal al invadir la competencia de las entidades al señalar que las participaciones podrán ser fiscalizadas desde la federación y dar paso a la acción directa de la Auditoría Superior de la Federación ASF si así, lo considerase necesario, según se puede apreciar en lo establecido en la precitada Fracción I. En vez de proponer coadyuvar en la mejora en la fiscalización local, que en ciertos casos es necesaria, desoyendo el reclamo al respecto, entre otros, del diputado por el Partido de la Revolución Democrática PRD ${ }^{14}$.

${ }^{13}$ Artículo 79. La Auditoría Superior de la Federación de la Cámara de Diputados, tendrá autonomía técnica y de gestión en el ejercicio de sus atribuciones y para decidir sobre su organización interna, funcionamiento y resoluciones, en los términos que disponga la ley.

La Auditoría Superior de la Federación tendrá a su cargo:

I. ...

También fiscalizará directamente los recursos federales que administren o ejerzan los estados, los municipios, el Distrito Federal y los órganos políticoadministrativos de sus demarcaciones territoriales. En los términos que establezca la ley fiscalizará, en coordinación con las entidades locales de fiscalización o de manera directa, las participaciones federales. En el caso de los Estados y los Municipios cuyos empréstitos cuenten con la garantía de la Federación, fiscalizará el destino y ejercicio de los recursos correspondientes que hayan realizado los gobiernos locales. Asimismo, fiscalizará los recursos federales que se destinen y se ejerzan por cualquier entidad, persona física o moral, pública o privada, y los transferidos a fideicomisos, fondos y mandatos, públicos y privados, o cualquier otra figura jurídica, de conformidad con los procedimientos establecidos en las leyes y sin perjuicio de la competencia de otras autoridades y de los derechos de los usuarios del sistema financiero.

${ }^{14}$ En el debate parlamentario previo a la aprobación del SNA, el diputado por Michoacán Víctor Manuel Manríquez González del Partido de la Revolución Democrática PRD denunció............ vengo a reiterar que nosotros estamos a 
2) Uno de los problemas que aquejan tanto a las Tesorerías municipales como Estatales, es la ausencia de confianza de que la federación les entregue la cantidad que les corresponde en la recaudación federal del impuesto al valor agregado, el impuesto sobre la renta, el impuesto especial sobre producción y servicios, en la participación para la seguridad e igual con otras participaciones.

Premisas de lo anterior lo son 1) la ausencia de homogeneidad en la asunción al poder de los gobiernos federal, de las entidades federativas y de los municipios -previos procesos electorales--; 2) la complejidad, diversidad, y dispersidad de las formulas [contempladas tanto en la Ley de Coordinación Fiscal LCF y en sus homólogas, en los presupuestos de Egresos, en las Misceláneas Fiscales y demás ordenamientos fiscales], que requiere de un nivel de especialización que dificulta su verificación por las entidades federativas y una gran cantidad de municipios, aunado, en la mayoría de los casos, al 3) desconocimiento de los

favor del combatir la corrupción. , por eso votamos a favor este dictamen en lo general. Sin embargo el aprobar estas reformas constitucionales no nos limita para exponer que ....... la inquietud más grande que tengo se refiere al federalismo, yo no estoy de acuerdo en disminuir la capacidad y actuación de los gobiernos estatales y municipales y se le traslade la responsabilidad a la federación.........Hemos cedido parte de la soberanía en otros problemas y ha sido contraproducente. Se diga cómo se diga en la práctica, somos un país centralista, un centralismo con una cara autoritaria. Eso me preocupa mucho porque hemos visto una y otra vez la tentación por parte de la federación en ejercer un control político, hemos sido testigos de la presentación(sic) de castigar a quienes tengan una posición diferente a la federación. Por eso no estoy a favor de que los estados le cedan la facultad a la federación para fiscalizar las participaciones federales que son recursos propios de los estados. No se resuelve el problema señalando que ahora será la Auditoría Superior de la Federación, la que realice esta actividad. Hasta hoy la auditoría no ha evitado la corrupción......Existe una profunda desconfianza en las acciones del gobierno federal, ..... Por tal motivo, propongo ...... que no deleguemos, ni centralicemos la fiscalización, les pido que fortalezcamos a los órganos de control locales, generemos verdaderos contrapesos en las entidades federativas y municipios. Fortalezcamos los órdenes de gobierno locales, no debilitemos el federalismo... Diputados Discusión México, D.F., jueves 26 de febrero de 2015. Versión Estenográfica, pp.86 consultado [on line] Disponible en:

http://legislacion.scjn.gob.mx/Buscador/Paginas/AbrirDocProcLeg.aspx? IdLey=130 \&ldRef=241\&IdProcLeg $=3 \& I d P d f=00001300024100003 . p d f$ 
nuevos y en ocasiones improvisados funcionarios, que auxiliarán a los también recientemente electos funcionarios en el mas alto nivel de los gobiernos federal, locales y municipales. Verbigracia, "en la Ley de Ingresos de la Federación que se aprueba año con año por el Congreso de la Unión, aparecen con baja recaudación bajo el rubro de impuestos no comprendidos en las fracciones de la Ley de Ingresos causados en ejercicios fiscales anteriores pendientes de liquidación de pago -5,083.1, no obstante que el Servicio de Administración Tributaria alude durante el ejercicio fiscal de la percepción de miles de millones de pesos en dicho rubro. ${ }^{15}$.

3) Acorde al "Diagnóstico sobre la opacidad en el gasto federalizado" "realizado por la Auditoría Superior de la Federación ASF en el $2013^{17}$, una de las áreas de opacidad detectadas, son "las debilidades en los sistemas de control interno de las entidades federativas y de manera significativa en el caso de los municipios". Y si bien-- en dicho diagnóstico -- se menciona, que la federación contribuye a ello, por no entregar en tiempo y con transparencia los recursos denominados

15 MARGAIN MANATOU E., El Municipio: Su Situación Económica,BIOLEX Revista Juridica del Departamento de DERECHO UNISON, Academia de Derecho Administrativo, Tercera Época Año 8. No 14 Enero - Junio de 2016,pp. 1

${ }^{16}$ Documento en el que se señala de manera puntual cuáles son las áreas que se consideran de mayor riesgo para la transparencia, fiscalización y rendición de cuentas. También se indica que el gasto federalizado es relevante para las finanzas estatales y municipales; puesto que en el 2013 para los gobiernos de los estados significó en promedio el $90 \%$ de sus ingresos totales y para los municipios alrededor del 65\%, aunque en los rurales y marginados superó el $90 \%$.

17 Conforme al decreto que modifica la Ley General de Contabilidad Gubernamental (LGCG), publicado el 12 de noviembre de 2012, en su artículo Octavo Transitorio se dispone que la Auditoría Superior de la Federación enviará a las Comisiones de Hacienda del Senado de la República y de la Cámara de Diputados así como a las Comisiones de la Función Pública, de Presupuesto y Cuenta Pública y de Vigilancia de la Auditoria Superior de la Federación de la Cámara de Diputados en un plazo no mayor a 6 meses a partir de la entrada en vigor del presente Decreto, un diagnóstico que señala las áreas de opacidad en la ejecución del gasto federalizado y una propuesta de modificación al marco jurídico para transparentar aún más el ejercicio de dicho gasto y mejorar los resultados del mismo. 
gasto federalizado, cabe cuestionarse ¿porqué en el mismo informe o en otro diverso no se realizó --con la misma exhaustividad --, el "diagnóstico sobre la opacidad en la asignación y distribución de recursos por parte de la federación a Entidades Federativas y Municipios"?

Los problemas de la transparencia y la rendición de cuentas en la gestión, asignación, distribución y ejercicio de los recursos públicos, no solo obedece a vacíos, ambigüedades o inexistencia en la normativa de las disposiciones sobre la operación de los fondos o programas, sino a insuficiencias o debilidades en la coordinación intergubernamental e interinstitucional, además de las que surgen de la inobservancia por funcionarios de los tres órdenes de gobierno, de la normativa existente, en la materia.

4) En este tenor, cabe mencionar que la Ley de Coordinación Fiscal LCF si bien ha sido revisada en diversas ocasiones, ello ha ocurrido no con el alcance necesario para adecuarla a las actuales circunstancias de las entidades federativas y municipios, por lo que algunas de sus disposiciones están rebasadas en aspectos sustantivos, como es el caso del impacto de las múltiples reformas a la Constitución Política de los Estados Unidos mexicanos CPEUM durante el presente siglo XXI. Esta situación afecta la transparencia de la asignación, distribución y ejecución del gasto federalizado.

5) En cuanto al incumplimiento de la normativa, los subejercicios constituyen un importante problema en la transparencia, debido a que --- según lo señala el jurisconsulto Don Emilio Margáin--- no se tiene la certeza que los recursos que no son ejercidos con oportunidad se destinan a los fines y objetivos previstos; asimismo, se dificulta su fiscalización posterior. Esto es, existen en nuestro país municipios considerados pobres a los que la federación les ofrece participar en inversiones municipales pero a su vez a ellos les corresponde aportar cantidades (desde diez, veinte o cincuenta mil pesos) que aun, cuando parezcan cantidades alcanzables, tienen que rechazar tal participación al carecer de los recursos en cantidades líquidas, es decir, hay municipios económicamente tan desfavorecidos, 
que no pueden aceptar participaciones federales al no poder aportar lo que se les pide, casos en los cuales el Estado debe de acudir en auxilio de ellos. ${ }^{18} \mathrm{~A}$ esta situación abona también las dilaciones en la suscripción de convenios o anexos de ejecución que condicionan la asignación y ejercicio de los recursos.

La grave situación por la que atraviesa nuestro país en temas como la corrupción --que en este Congreso nos ocupa--, nos obliga a replantear no sólo las políticas y estrategias que se han diseñado para combatirlas, sino la urgente revisión de todo el sistema estructural en que se sustenta el Estado Mexicano. Ello incluye replantear ciertos principios constitucionales que hacen la diferencia jurídica entre una república, representativa democrática federal (Art.40 CPEUM) o una república representativa democrática central (vbg. Francia), evitando con ello el triangular situaciones o modificar normatividad ${ }^{19}$, tratando de guardar las formas exigidas

${ }^{18}$ Margain Manautou Emilio , El Municipio: Su Situación Económica, BIOLEX Revista Jurídica del Departamento de Derecho UNISON URC, Academia de Derecho Administrativo, Tercera Época Año 8. No 14 Enero - Junio de 2016, pp 9.

${ }^{19}$ En el debate parlamentario previo a la aprobación del SNA, el diputado por Michoacán Víctor Manuel Manríquez González del Partido de la Revolución Democrática PRD denunció............ vengo a reiterar que nosotros estamos a favor del combatir la corrupción. ........., por eso votamos a favor este dictamen en lo general. Sin embargo el aprobar estas reformas constitucionales no nos limita para exponer que ...... la inquietud más grande que tengo se refiere al federalismo, yo no estoy de acuerdo en disminuir la capacidad y actuación de los gobiernos estatales y municipales y se le traslade la responsabilidad a la federación.... Hemos cedido parte de la soberanía en otros problemas y ha sido contraproducente. Se diga cómo se diga en la práctica, somos un país centralista, un centralismo con una cara autoritaria. Eso me preocupa mucho porque hemos visto una y otra vez la tentación por parte de la federación en ejercer un control político, hemos sido testigos de la presentación(sic) de castigar a quienes tengan una posición diferente a la federación. Por eso no estoy a favor de que los estados le cedan la facultad a la federación para fiscalizar las participaciones federales que son recursos propios de los estados. No se resuelve el problema señalando que ahora será la Auditoría Superior de la Federación, la que realice esta actividad. Hasta hoy la auditoría no ha evitado la corrupción......Existe una profunda desconfianza en las acciones del gobierno federal, ..... Por tal motivo, propongo ...... que no deleguemos, ni centralicemos la fiscalización, les pido que fortalezcamos a los órganos de control locales, 
por un Estado de Derecho "cuya sustancia es la protección de las áreas de la autonomía individual delimitada por los derechos humanos ....lo que permite reconocer ..... que no todos los Estados son Estados de Derecho. Es cierto que todos producen normas jurídicas que son utilizadas por los sujetos para componer intereses y dirimir conflictos, pero se requiere algo mas para alcanzar la forma de Estado de Derecho. Es preciso que la acción de los poderes del Estado esté sometido a las leyes, esto es, que el Estado actúe sujeto a su propio Derecho. ${ }^{20 "}$ Parafraseando a Sanz Burgos ....es decir, "sujeto a un Derecho generado a través de procedimientos que articulan la participación ciudadana y que sea acorde a los valores que tutelan el sistema."

Frente a esta realidad, es necesario que federación, entidades federativas y municipios, con la participación del sector ciudadano organizado conjuntamente, tomen cargo del combate a la corrupción trabajando, en el reciente nacido SNA bajo una misma visión, con similares estándares, valores éticos y capacidades técnicas en la revisión de la gestión, asignación distribución y ejercicio de los recursos públicos, para evitar prácticas de corrupción en todos los niveles de gobierno y preservar con ello el Estado de Derecho.

\section{Conclusiones}

Si bien la reforma constitucional que da origen al SNA contempla los mecanismos de coordinación y colaboración entre los tres órdenes de gobierno para el combate a la corrupción, en algunos aspectos muy específicos, se invade la esfera de competencias de los estados y municipios, como es el caso de la fiscalización de

generemos verdaderos contrapesos en las entidades federativas y municipios. Fortalezcamos los órdenes de gobierno locales, no debilitemos el federalismo... Diputados Discusión México, D.F., jueves 26 de febrero de 2015. Versión Estenográfica, pp.86 consultado [on line] Disponible en: http://legislacion.scjn.gob.mx/Buscador/Paginas/AbrirDocProcLeg.aspx?ldLey=130 \&ldRef $=241 \&$ IdProcLeg $=3 \& I d P d f=00001300024100003$.pdf

${ }^{20}$ SANZ BURGOS, Raúl, El Derecho y la Etica Publica, en Etica y Deontologias Públicas Junquuera de Estéfani R. et al., Ed. Universitas S.A. Madrid 2011,pp.143 
las participaciones.

La tendencia que ha venido tomando el legislador es hacia una mayor concentración de atribuciones en favor de las autoridades federales, socavando el pacto federal al centralizar aún más el combate a la corrupción.

La grave situación por la que atraviesa nuestro país en temas como la corrupción --que en este Congreso nos ocupa--, nos obliga a replantear no sólo las políticas y estrategias que se han diseñado para combatirlas, sino la urgente revisión de todo el sistema estructural en que se sustenta el Estado Mexicano.

Ello incluye replantear ciertos principios constitucionales que hacen la diferencia jurídica entre una república, representativa democrática federal (Art.40 CPEUM) o una república representativa democrática central (vbg. Francia), evitando con ello el triangular situaciones o modificar normatividad, tratando de guardar las formas exigidas por un Estado de Derecho.

Para alcanzar la forma de Estado de Derecho. Es preciso que la acción de los poderes del Estado esté sometida a las leyes, esto es, que el Estado actúe sujeto a su propio Derecho....es decir, "sujeto a un Derecho generado a través de procedimientos que articulan la participación ciudadana y que sea acorde a los valores que tutelan el sistema."

\section{Bibliografía}

FERNANDEZ RUIZ J., en Justicia Constitucional Local, Corona Nakamira L.A. et al . Coed Instituto Prisciliano Sánchez - UNAM, México, 2013

MARGAIN MANAUTOU E., EI Municipio: Su Situación Económica,BIOLEX Revista Juridica del Departamento de DERECHO UNISON, Academia de Derecho Administrativo, Tercera Época Año 8. No 14 Enero - Junio de 2016 Ed.Porrua,Mexico,2013 Introducción al Estudio del Derecho Tributario,

RODRIGUEZ -ARANA,J., Cuestiones deontológicas en torno al trabajo en la Administración Pública, en Ética de las Profesiones Jurídicas Vol. Dos, 
Universidad católica de Murcia 2003, citado por Junquera de Estéfani R., et al, en Ética y Deontología Públicas, Ed.Universitas,S.A., Madrid , 2011

SANZ BURGOS, Raúl, El Derecho y la Etica Publica, en Etica y Deontologias Públicas Junquera de Estéfani R. Et al. Ed. Universitas S.A. Madrid 2011

\section{Webgrafía}

Cámara de Diputados - ASF, 2013.

http://www.asf.gob.mx/uploads/56_Informes_especiales_de_auditoria/Diagnostico _sobre_I a_Opacidad_en_el_Gasto_Federalizado_version_final.pdf

Diputados Discusión México, D.F., jueves 26 de febrero de 2015. Versión Estenográfica, http://legislacion.scjn.gob.mx/Buscador/Paginas/AbrirDocProcLeg.aspx?ldLey=130 \&ldRef=241\&IdProcLeg=3\&IdPdf=00001300024100003.pdf

Instituto Mexicano para la Competitividad IMCO Índice de Percepción de la Corrupción 2015 vía Transparencia Internacional 
BIOLEX Revista Jurídica del Departamento de Derecho UNISON URC

Academia de Derecho Administrativo

Tercera Época Año 8, No.15, Julio -Diciembre de 2016

\section{Anexo 1}

\section{Rompe la Cadena de la Corrupción www.anticorruptionday.org}

\begin{tabular}{|c|c|c|}
\hline \multirow{6}{*}{$\begin{array}{l}\text { El sector privado } \\
\text { puede combatir la } \\
\text { corrupción y... }\end{array}$} & $\begin{array}{l}\text { Fortalecer la } \\
\text { democracia... }\end{array}$ & $\begin{array}{l}\text { Fomentando la estabilidad económica mediante prácticas de tolerancia cero } \\
\text { respecto de la corrupción. Una comunidad empresarial transparente y abierta es la } \\
\text { piedra angular de toda democracia sólida. }\end{array}$ \\
\hline & $\begin{array}{l}\text { Promover la } \\
\text { justicia... }\end{array}$ & $\begin{array}{l}\text { Promulgando políticas relativas a los regalos, las cadenas de suministro, los } \\
\text { denunciantes de irregularidades y otras cuestiones importantes relacionadas con la } \\
\text { corrupción, y sensibilizando a todos los empleados al respecto. } \\
\text { El desempeño de los empleados mejorará si sienten confianza en la justicia y } \\
\text { equidad del entorno en que se desenvuelven. }\end{array}$ \\
\hline & $\begin{array}{l}\text { Apoyar la } \\
\text { educación... }\end{array}$ & $\begin{array}{l}\text { Financiando programas de educación y asegurando que estos se administren en } \\
\text { forma justa. } \\
\text { Apoyar un sistema educativo sólido mediante donaciones y actividades de } \\
\text { divulgación es una buena inversión en el futuro. }\end{array}$ \\
\hline & $\begin{array}{l}\text { Crear } \\
\text { prosperidad... }\end{array}$ & $\begin{array}{l}\text { Aplicando en forma estricta medidas de lucha contra la corrupción y recurriendo a } \\
\text { auditores independientes para asegurar su cumplimiento. Aplique "estrategias de } \\
\text { lucha contra la corrupción" en el diálogo social (véase Los sindicatos). } \\
\text { En el sector privado, la corrupción aumenta los gastos de las empresas por el } \\
\text { "impuesto" complementario que representan los sobornos, el gasto administrativo } \\
\text { adicional de las negociaciones con funcionarios corruptos y las sanciones jurídicas y } \\
\text { financieras por el incumplimiento de acuerdos o el descubrimiento de la comisión de } \\
\text { un delito. }\end{array}$ \\
\hline & $\begin{array}{l}\text { Salvaguardar el } \\
\text { desarrollo... }\end{array}$ & $\begin{array}{l}\text { Respetando las normas de competencia leal. } \\
\text { La corrupción puede poner a empresas de dudosa reputación a salvo de la } \\
\text { competencia leal y, por lo tanto, permitir que las empresas ineficientes sobrevivan } \\
\text { en el mercado y lo distorsionen. }\end{array}$ \\
\hline & $\begin{array}{l}\text { Mejorar la salud } \\
\text { pública... }\end{array}$ & $\begin{array}{l}\text { Asegurando que las empresas de atención sanitaria adopten buenas prácticas } \\
\text { internacionales, a fin de que ofrezcan servicios y suministros médicos que } \\
\text { beneficien a todos los ciudadanos, en vez de ignorar las prácticas corruptas en el } \\
\text { sector público para obtener ganancias. } \\
\text { Por ejemplo, permitir por ambición que entren en el mercado medicamentos } \\
\text { adulterados significa poner en peligro a la sociedad entera. }\end{array}$ \\
\hline \multirow[b]{4}{*}{$\begin{array}{l}\text { Los sindicatos } \\
\text { pueden combatir la } \\
\text { corrupción y... }\end{array}$} & $\begin{array}{l}\text { Fortalecer la } \\
\text { democracia... }\end{array}$ & $\begin{array}{l}\text { Negociando remuneraciones decentes para los funcionarios públicos. } \\
\text { Asegurar que los funcionarios públicos reciban una remuneración decente, que } \\
\text { tengan dinero en el bolsillo, contribuye ampliamente a combatir la tentación de que } \\
\text { se llenen los bolsillos con sobornos. }\end{array}$ \\
\hline & $\begin{array}{l}\text { Promover la } \\
\text { justicia... }\end{array}$ & $\begin{array}{l}\text { Defendiendo a los denunciantes de irregularidades. } \\
\text { Proteja a quienes arriesgan su vida y sus medios de subsistencia para } \\
\text { desenmascarar a las personas corruptas y llevarlas ante los tribunales. El número } \\
\text { de denunciantes de irregularidades aumentará cuando sea evidente que no se } \\
\text { corren riesgos al exponer la corrupción. }\end{array}$ \\
\hline & $\begin{array}{l}\text { Apoyar la } \\
\text { educación... }\end{array}$ & $\begin{array}{l}\text { Vigilando la integridad de los sistemas de educación. } \\
\text { Los maestros no solo enseñan a nuestros hijos y los cuidan; también protegen la } \\
\text { buena reputación del sistema del que todos dependemos en beneficio de nuestros } \\
\text { hijos. }\end{array}$ \\
\hline & $\begin{array}{l}\text { Crear } \\
\text { prosperidad... }\end{array}$ & $\begin{array}{l}\text { Aplicando estrategias de lucha contra la corrupción en el diálogo social y } \\
\text { estableciendo alianzas con el sector empresarial para que impere la tolerancia cero } \\
\text { a las prácticas corruptas. } \\
\text { Un entorno empresarial libre de corrupción resulta más atractivo no solo para los } \\
\text { empleados, sino también para los posibles clientes. }\end{array}$ \\
\hline
\end{tabular}


BIOLEX Revista Jurídica del Departamento de Derecho UNISON URC

Academia de Derecho Administrativo

Tercera Época Año 8, No.15, Julio -Diciembre de 2016

Salvaguardar el Movilizando contra la corrupción la voz colectiva y el poder de negociación de los desarrollo... sindicatos.

Proteger y fomentar sociedades justas y transparentes, mediante acciones colectivas, contribuye enormemente al desarrollo y reduce la pobreza.

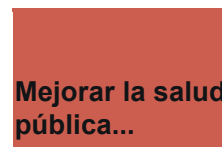

Luchando por remuneraciones justas y buenas condiciones de trabajo para los trabajadores sanitarios, así como por mejores servicios.

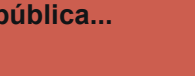

Los sindicatos de trabajadores de la salud pueden mejorar el sistema de atención médica y las condiciones laborales de los trabajadores, para que sean menos vulnerables a la corrupción. Asimismo, pueden ayudar a erradicar la corrupción, adoptando un enfoque de tolerancia cero de sus afiliados frente a la corrupción. Informándonos acerca del estado de derecho y de lo que el gobierno se ha comprometido a hacer para luchar contra la corrupción.

Fortalecer la Formar parte de una red de ciudadanos informados no solo resulta decisivo para democracia... toda democracia próspera: también lleva a considerar a las autoridades elegidas responsables de sus actos.

Promover la

Denunciando los casos de corrupción a las autoridades.

justicia...

Al presentar una denuncia, no solo se enfrenta a los corruptos, sino que también se defiende a la comunidad.

Apoyar la Enseñando a los niños que la corrupción es inaceptable. Los padres pueden enseñar a sus hijos el valor de la integridad.

Rehusando el pago o la aceptación de sobornos, honorarios de facilitación o

Todos podemos Crear regalos.

combatir la corrup- prosperidad...

El rechazo o de recompensas ilícitas por una labor realizada o por realizar, ción y... sino también a quienes colaboran con ellos.

$\begin{array}{ll}\text { Salvaguardar el } & \begin{array}{l}\text { Diciendo a las autoridades elegidas que la lucha contra la corrupción debería formar } \\ \text { parte integrante de todas las políticas de desarrollo. } \\ \text { Usted tiene no solo el derecho, sino también la responsabilidad, de recordar a } \\ \text { qesarrollo... }\end{array} \\ \begin{array}{l}\text { quienes ha elegido para ocupar un cargo que lo representan a usted, a su } \\ \text { comunidad y sus ideales, tanto en el país como en el extranjero. }\end{array} \\ \begin{array}{ll}\text { Exigiendo acceder fácilmente a información transparente sobre la atención médica, } \\ \text { por ejemplo, sobre los servicios a que tienen derecho los ciudadanos y sobre el } \\ \text { costo de esos servicios. }\end{array} \\ \begin{array}{ll}\text { Mejorar la salud acceso a la atención sanitaria básica es un derecho de todo ciudadano. Un } \\ \text { pública... }\end{array} \\ \begin{array}{l}\text { Eludadano responsable se caracteriza por conocer sus derechos y formular las } \\ \text { preguntas debidas. }\end{array}\end{array}$

